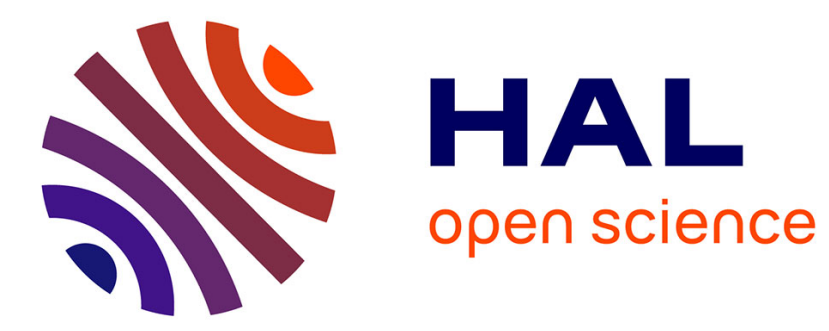

\title{
Magnetoelectric properties of nickel nanowires-P(VDF-TrFE) composites
}

Thanh Hoai Lucie Nguyen, Lydia Laffont-Dantras, Jean-Fabien Capsal, Pierre-Jean Cottinet, Antoine Lonjon, Eric Dantras, Colette Lacabanne

\section{To cite this version:}

Thanh Hoai Lucie Nguyen, Lydia Laffont-Dantras, Jean-Fabien Capsal, Pierre-Jean Cottinet, Antoine Lonjon, et al.. Magnetoelectric properties of nickel nanowires-P(VDF-TrFE) composites. Materials Chemistry and Physics, 2015, vol. 153, pp. 195-201. 10.1016/j.matchemphys.2015.01.003 . hal01110634

\section{HAL Id: hal-01110634 \\ https://hal.science/hal-01110634}

Submitted on 28 Jan 2015

HAL is a multi-disciplinary open access archive for the deposit and dissemination of scientific research documents, whether they are published or not. The documents may come from teaching and research institutions in France or abroad, or from public or private research centers.
L'archive ouverte pluridisciplinaire HAL, est destinée au dépôt et à la diffusion de documents scientifiques de niveau recherche, publiés ou non, émanant des établissements d'enseignement et de recherche français ou étrangers, des laboratoires publics ou privés. 


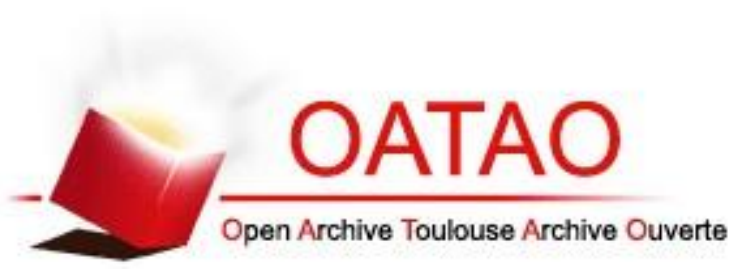

Open Archive Toulouse Archive Ouverte (OATAO)

OATAO is an open access repository that collects the work of Toulouse researchers and makes it freely available over the web where possible.

This is an author-deposited version published in: http://oatao.univ-toulouse.fr/ Eprints ID: 13305

Identification number: DOI:10.1016/j.matchemphys.2015.01.003

Official URL: http://dx.doi.org/10.1016/j.matchemphys.2015.01.003

\section{To cite this version:}

Nguyen, Thanh Hoai Lucie and Laffont, Lydia and Capsal, Jean-Fabien and Cottinet, Pierre-Jean and Lonjon, Antoine and Dantras, Eric and Lacabanne, Colette Magnetoelectric properties of nickel nanowires-P(VDF-TrFE) composites. (2015) Materials Chemistry and Physics, vol. 153 . pp. 195-201. ISSN 0254-0584

Any correspondence concerning this service should be sent to the repository administrator: staff-oatao@inp-toulouse.fr 


\title{
Magnetoelectric properties of nickel nanowires-P(VDF-TrFE) composites
}

\author{
Thanh Hoai Lucie Nguyen ${ }^{\mathrm{a}}$, Lydia Laffont ${ }^{\mathrm{b}}$, Jean-Fabien Capsal ${ }^{\mathrm{c}}$, Pierre-Jean Cottinet ${ }^{\mathrm{c}}$, \\ Antoine Lonjon ${ }^{a}$, Eric Dantras ${ }^{\text {a, }}{ }^{*}$, Colette Lacabanne ${ }^{a}$ \\ a Physique des Polymères, CIRIMAT - Institut Carnot, Université Paul Sabatier, 118 Route de Narbonne, 31062 Toulouse Cedex 9, France \\ b MEMO, CIRIMAT/Institut Carnot, ENSIACET, 4 Allée Emile Monso, BP 44362, 31030 Toulouse Cedex 4, France \\ ${ }^{\mathrm{c}}$ LGEF-INSA Lyon, 8 Rue de la Physique, 69621 Villeurbanne Cedex, France
}

\section{H I G H L I G H T S}

- A magnetic anisotropy of the ferromagnetic Ni nanowires was observed.

- The $\mathrm{P}(\mathrm{VDF}-\mathrm{TrFE})$ glass transition has an influence on the NWs Ni/P(VDF-TrFE) $0.3 \%$ vol composite magnetic properties.

- The NWs Ni/P(VDF-TrFE) composite was polarized to obtain a significant piezoelectric coefficient of $7 \mathrm{pC} \mathrm{N}^{-1}$.

- The magnetoelectric coefficient reached the high value of $237 \mathrm{~V} /(\mathrm{m} \mathrm{Oe})$.

Keywords:

Magnetic properties

Piezoelectricity

Ferroelectricity

Polymers

Composite materials

\section{A B S T R A C T}

Multiferroic composites with very high magnetoelectric coupling composites have been elaborated by incorporating high aspect ratio magnetic nickel particles in a ferroelectric matrix P(VDF-TrFE). Nickel nanowires (NWs) were elaborated by the electrodeposition method which allows obtaining a constant aspect ratio of 250. SEM-FEG images showed a Ni NWs homogeneous dispersion in acetone or in the P(VDF-TrFE). HR-TEM images and electronic diffraction studies revealed that the Ni NWs are monocrystalline, thanks to the electrodeposition method. Magnetic measurements showed a strong anisotropy of the magnetic particles, the coercivity is higher in the parallel direction (160 Oe). This anisotropy decreased for the composites due to the diminution of the Ni NWs interactions. The piezoelectric coefficient obtained after the composite polarization was significant $\left(7 \mathrm{pC} \mathrm{N}^{-1}\right)$ under a polarization field of $60 \mathrm{kV} \mathrm{mm}^{-1}$. The magnetoelectric coefficient reached the value of $237 \mathrm{~V} /(\mathrm{m} \mathrm{Oe})$ at $4 \mathrm{kHz}$. According to the previous studies, this value is the highest one found for multiferroic polymer matrix composites.

\section{Introduction}

Magnetoelectric effect (ME) is the combined properties of magnetostriction (MS) and piezoelectricity (PE) behavior [1,2]. By coupling these both properties, it is possible to perform a change of electric polarization upon applying magnetic field (direct ME effect) or, in return, to obtain a change of magnetization under an electric field (indirect ME effect) [3,4]. Two ways have been explored: the intrinsic one with multiferroic materials and the extrinsic one with magnetoelectric composites. Preparation and characterization of ME multiferroic materials have attracted much

\footnotetext{
* Corresponding author.

E-mail address: eric.dantras@univ-tlse3.fr (E. Dantras).
}

interest in research for functionalized materials and devices. They have been widely used as data storage devices [5,6], magnetic sensors, transducers and actuators [7]. The previously elaborated composites which present the higher ME coefficients are mostly for ceramic composites. For example, a multilayer composite terfenol$\mathrm{D} / \mathrm{PZT} /$ terfenol-D has an ME coefficient of $600 \mathrm{~V} /(\mathrm{m} \mathrm{Oe})$ [8], another multilayer composite $\mathrm{Ni} / \mathrm{PZT} / \mathrm{Ni}$ has $150 \mathrm{~V} /(\mathrm{m} \mathrm{Oe})$ [9], all measured at resonance frequency. These composites are made of a piezoelectric material and a magnetostrictive material. This extrinsic approach, ferromagnetic particles in organic ferroelectric matrix, could lead to revolutionary device applications due to their intrinsic low-cost, lightweight, and flexible features [10]. In previous works, ferroelectric matrices have been used to elaborate ME composites as multilayers [10-12] and 3-0 composites where 
particles are dispersed in a matrix $[13,14]$.

Recently, magnetic nanowires have been widely studied because of their promising applications in the perpendicular and parallel measurement direction [15-17]. One promising technic to elaborate such magnetic nanowires is the electrodeposition [18-21]. During the process, the lateral growths of deposited ferromagnetic materials are bounded by the pore walls so as to form the desired nanowire arrays.

In this work, ferromagnetic Ni nanowires (NWs) will be prepared by electrochemical deposition in an anodic aluminate oxide (AAO) porous template. This method allows obtaining 250 aspect ratio NWs with negligible size dispersion. They will be introduced in a ferroelectric organic matrix $\mathrm{P}(\mathrm{VDF}-\mathrm{TrFE})$ in a concentration of 0.3 vol\%. Ferromagnetic and ferroelectric properties will be studied for Ni NWs and neat $\mathrm{P}(\mathrm{VDF}-\mathrm{TrFE})$. These measurements will also be performed on $\mathrm{P}(\mathrm{VDF}-\mathrm{TrFE}) / \mathrm{Ni} \mathrm{NWs}$ nanocomposites to determine their ferromagnetic and ferroelectric behavior. The $\mathrm{P}(\mathrm{VDF}-\mathrm{TrFE}) / \mathrm{Ni} \mathrm{NWs}$ nanocomposite magnetoelectric coefficient will be determined.

\section{Experimental}

\subsection{Materials}

Magnetic nanowires (NWs) were prepared by electrochemical deposition in an anodic aluminum oxide (AAO) porous template. The electrolyte used for the deposition was a standard Watts bath with an accurate $\mathrm{pH}$ value of 4 . Direct current (DC) electrodeposition was carried out at room temperature using a $\mathrm{Ni}$ wire as anode with $2.0 \mathrm{~mm}$ in diameter. A $200 \mathrm{~nm}$ diameter and $50 \mu \mathrm{m}$ thickness porous AAO membrane was supplied by Whatman. One side of the AAO membrane was coated with a $35 \mathrm{~nm}$ thickness silver layer by using sputtering technique as cathode for electrodeposition. The NWs growing was controlled by the time deposition and the direct current intensity using a Keithley 2420 source meter. The AAO filled membrane was dissolved in $\mathrm{NaOH}$ solution $(6 \mathrm{M})$ for $30 \mathrm{~min}$, releasing the NWs from the template. The NWs were washed with distilled water, filtrated and well dispersed in acetone under sonication for $5 \mathrm{~s}$, corresponding to a dissipated power of $25 \mathrm{~W}$.

Poly(vinylidenefluoride-trifluoroethylene) $\mathrm{P}(\mathrm{VDF}-\mathrm{TrFE}) \quad(70 /$ 30) mol\% copolymer was supplied by Piezotech S.A. (Hésingue, France).

\section{2. $P(V D F-T r F E) / N i$ NWs composites elaboration}

The nanocomposites were prepared by using solvent casting method. $\mathrm{P}(\mathrm{VDF}-\mathrm{TrFE})$ was dissolved in acetone under magnetic stirring at $80^{\circ} \mathrm{C}$ for $1 \mathrm{~h}$. The Ni NWs acetone suspension was poured into the polymer solution and the mixture was submitted to $5 \mathrm{~s}$ short pulse of sonication, corresponding to a dissipated power of $25 \mathrm{~W}$. The obtained suspension was precipitated with water. The obtained composite was placed in a steam at $80{ }^{\circ} \mathrm{C}$ in order to remove the totality of the solvent. The composite was pressed at $200{ }^{\circ} \mathrm{C}$ under a pressure of about $0.3 \mathrm{MPa} .80 \mu \mathrm{m}$ thickness films were obtained. No solvent residue was found by thermogravimetric analysis, indicating a complete removal of solvent from samples. $\mathrm{P}(\mathrm{VDF}-\mathrm{TrFE}) / \mathrm{Ni} \mathrm{NW}$ nanocomposites were elaborated with a volume fraction of $0.3 \mathrm{vol} \%$. This is the highest concentration of $\mathrm{Ni}$ NWs to get an insulating material that can be macroscopically polarized in our case.

\subsection{Scanning electron microscopy}

The morphology of Ni NWs was examined by scanning electron microscopy (SEM) using a JEOL JSM 6700F instrument equipped with a field emission gun (SEM-FEG). The composites were fractured at the liquid nitrogen temperature for observation by SEMFEG.

\subsection{High resolution transmission electron microscopy}

The structure and texture of Ni NWs crystallinity were determined by high resolution transmission electron microscopy (HRTEM). Ni NWs were dispersed in toluene and drop of the suspension was coated with lacey carbon films to obtain transparent sample for electron irradiation. TEM and HRTEM images were obtained by using a JEOL 2100F microscope. The diffraction patterns were obtained using the selected area electronic diffraction (SAED) mode.

\subsection{Magnetic properties characterization}

The measurements were performed with an MPMS 5 Quantum Design magnetometer (cryo-magnet $5 \mathrm{~T}$ and cryostat allowing sample temperatures from $2 \mathrm{~K}$ to $400 \mathrm{~K}$ ). The sample is placed between the detection coils in a $5 \mathrm{~mm}$ diameter straw, parallel or perpendicular to them and fixed with a cotton wire.

\subsection{Polarization and piezoelectric coefficient measurement}

The samples were placed between two conductive electrodes and poled by applying a sinusoidal voltage $\left(-55 \mathrm{kV} \mathrm{mm}^{-1}\right.$ or $+55 \mathrm{kV} \mathrm{mm}^{-1}$ ) between the two electrodes.

When a macroscopic polarization is obtained, the piezoelectric coefficient $\mathrm{d}_{33}$ is measured by a PM 200 piezometer from Piezotest. A sinusoidal strength is applied during the measurement. The $\mathrm{d}_{33}$ is a given by the following equation:

$d_{33}=\frac{\Delta P_{3}}{\Delta \sigma_{3}}$

where $\Delta \mathrm{P}_{3}$ is the measured polarization and $\Delta \sigma_{3}$ the applied stain.

\subsection{Magnetoelectric measurements}

To measure the magnetoelectric current, the sample is placed under a dynamic and a static magnetic fields [22]. The alternative magnetic field $\mathrm{H}_{\mathrm{ac}}$ is generated by a Helmholtz coil supplied by an audio amplifier (STA-700 Power Amplifier) which is led by a function generator (Agilent 33220A). The permanent magnetic field $\mathrm{H}_{\mathrm{dc}}$ is created by two electromagnets. Under the magnetic field, the sample is deformed and generates a current amplified by the current amplifier (Keithley 617) and observed on the oscilloscope. The magnetic field generated by the Helmholtz coils is measured by a Hall effect probe (Gauss/Teslameter, F.W. Bell Model 5080).

This measurement permits to calculate the ME coefficient $\alpha_{\mathrm{E}}$ using ME theory. The ME materials equation of state is a second order equation:

$P=\varepsilon E+\alpha_{p} H+\frac{1}{2} \beta H^{2}$

where $\mathrm{P}, \mathrm{E}, \mathrm{H}$ and $\varepsilon$ are the polarization, the electric field, the magnetic field and the material permittivity respectively. $\alpha_{\mathrm{P}}$ and $\beta$ are linear and bilinear polarization ME coefficients respectively. The electric field being inexistent, (2) becomes:

$P=\alpha_{p} H+\frac{1}{2} \beta H^{2}$

The ME current is determined by the following equation (4): 
$i=S \stackrel{\circ}{P}=\alpha_{p} S \cdot\left(H_{d c}^{\circ}+h_{a c}^{\circ}\right)+\beta S\left(H_{d c}+h_{a c}\right) \cdot\left(H_{d c}^{\circ}+h_{a c}^{\circ}\right)$

where $S$ is the electrodes surface in contact with the sample, $\mathrm{S}=15 \times 5 \mathrm{~mm}^{2}$.

Since $H_{d c}^{\circ}=0$, (4) can be written as:

$i=\alpha_{p} S h_{a c}^{\circ}+\beta S\left(H_{d c}+h_{a c}\right) h_{a c}^{\circ}$

$h_{a c}^{\circ}=j \omega h_{a c}$ and $h_{a c}=H_{a c} e^{j \omega t},(5)$ becomes:

$i=\alpha_{p} S j \omega H_{a c} e^{j \omega t}+\beta S j \omega H_{d c} H_{a c} e^{j \omega t}+\beta S j \omega H_{a c}^{2} e^{2 j \omega t}$

If $H_{d c}=0$, the current evolves linearly with the frequency $i=\alpha_{P} S j \omega h_{a c}$. The polarization ME coefficient $\alpha_{\mathrm{P}}$ can be determined by measuring i:

$\alpha_{p}=\frac{i}{S j \omega h_{a c}}=\frac{d P}{d t} \times \frac{d t}{d H}$

Physically, $\alpha_{\mathrm{P}}$ expresses the change of polarization relative to the variation of the magnetic field. To compare these data with literature, the stress ME coefficient $\alpha_{\mathrm{E}}$ has to be introduced:

$\alpha_{E}=\frac{d E}{d H}=\frac{\alpha_{p}}{\varepsilon_{0} \varepsilon_{r}}$

\section{Results}

The morphology and aspect ratio of Ni NWs were studied by SEM-FEG using secondary electrons detection mode. Dispersed NWs in acetone suspension are deposited on SEM pin. After acetone evaporation, NWs are shown in Fig. 1a. Fig. 1b presents a bundle of
Ni NWs still bound by the silver layer from the electrodeposition process.

Fig. 1c and d shows SEM-FEG cryofractures of the P(VDF-TrFE) matrix filled with 0.3 vol\% of Ni NWs. Films were fractured at liquid nitrogen temperature perpendicularly to the press direction. Using the backscattered electrons detection mode, bright domains show the Ni NWs dispersed in the $\mathrm{P}(\mathrm{VDF}-\mathrm{TrFE})$ matrix.

The structure and texture of Ni NWs have also been investigated by TEM and HRTEM in Fig. 2. The bright field image (Fig. 2a) shows the morphology of the NWs presenting a homogeneous surface associated with a punctual electronic diffraction. This diffraction pattern and the HRTEM image are characteristic of a monocrystalline NWs. The spacings in the SAED pattern are in good agreement with spacings of the fcc $\mathrm{Ni}$ (space group Fm-3m, $\mathrm{a}=3.5239 \AA$ ).

The magnetization hysteresis loops in Fig. 3a were measured at $300 \mathrm{~K}$ for Ni NWs embedded in the AAO template at two different magnetic field directions; i.e. parallel (out-of-plane with the AAO template) or perpendicular with the NWs long axis (in-plane with the AAO template) at 2, 100, 300 and $400 \mathrm{~K}$. When the magnetic field is parallel to Ni NWs direction, the NWs coercive field $\mathrm{H}_{\mathrm{C}}$ is 160 Oe and the squareness is 0.13 , which means that the remnant magnetization $M_{r}$ is $13 \%$ of the saturation magnetization $M_{s}$.

$\mathrm{P}(\mathrm{VDF}-\mathrm{TrFE}) / \mathrm{Ni} \mathrm{NW} 0.3 \mathrm{vol} \%$ magnetic hysteresis loop at $300 \mathrm{~K}$ is represented in Fig. $4 \mathrm{~b}$. Although the coercivity $\mathrm{H}_{\mathrm{C}}$ equal to $250 \mathrm{Oe}$ is identical in the two magnetic field directions, the squareness value is considerably higher when the magnetic field is parallel with the composite film. The values are 0.65 in the parallel direction and 0.14 in the perpendicular one.

The neat $\mathrm{P}(\mathrm{VDF}-\mathrm{TrFE})$ and the $\mathrm{P}(\mathrm{VDF}-\mathrm{TrFE}) / \mathrm{Ni} \mathrm{NW} 0.3$ vol\% composite ferroelectric hysteresis loops were measured and shown on Fig. 4. The applied electric field between the electrodes is strong enough to obtain well-defined hysteresis loops. The neat $\mathrm{P}(\mathrm{VDF}-\mathrm{TrFE})$ and its composite were submitted to a maximum
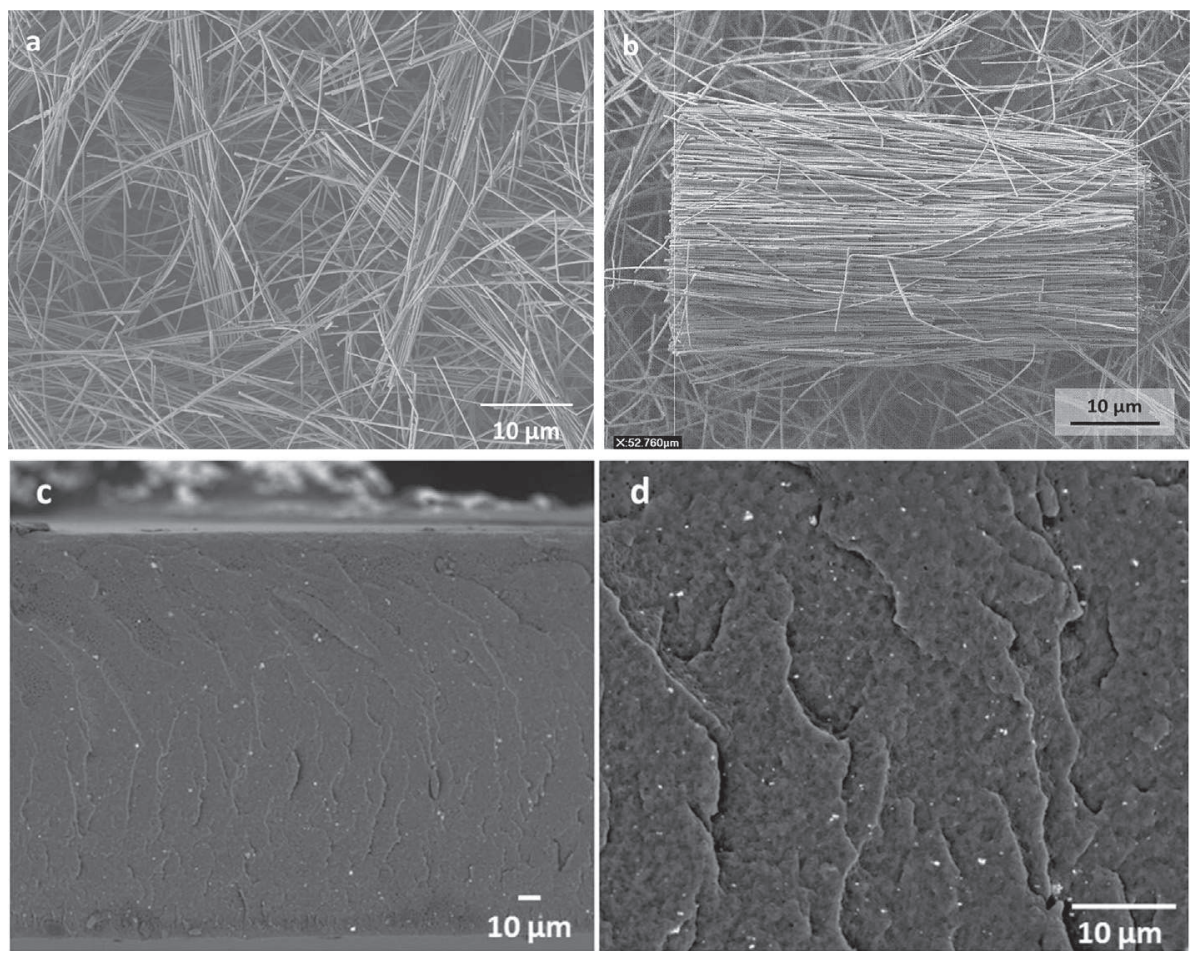

Fig. 1. SEM-FEG images of Ni NWs after dispersion in acetone (a), bound by the silver layer from the electrodeposition process (b), and cryofractures of composites P(VDF-TrFE)/Ni NWs 0.3 vol\% (c, d). 


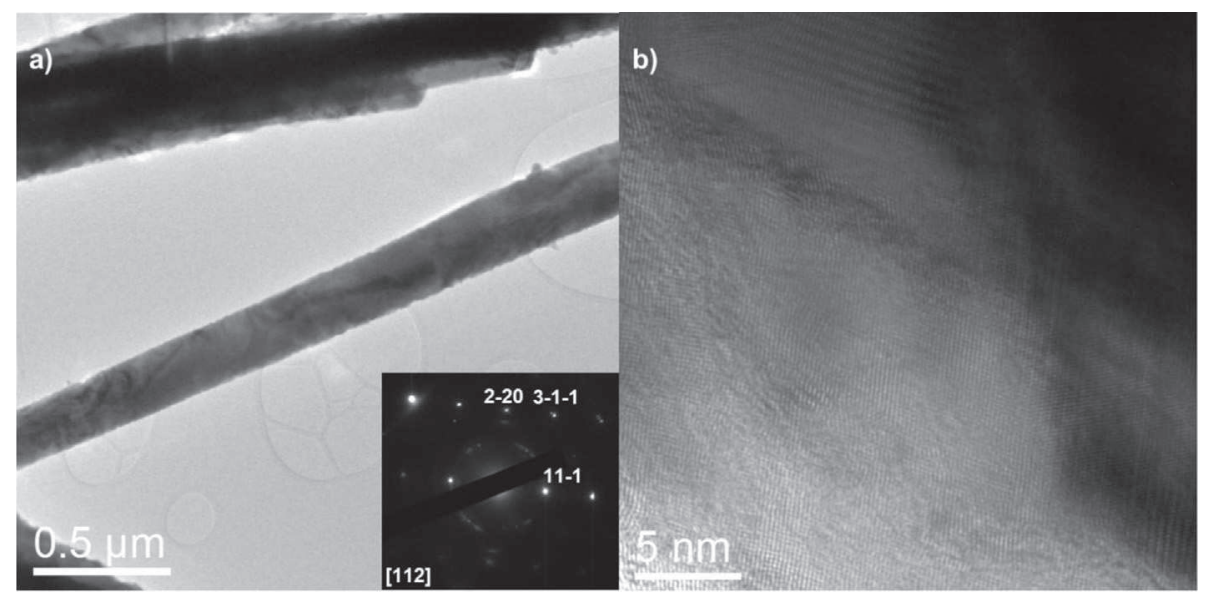

Fig. 2. a) Bright field TEM image of Ni NWs and this selected area diffraction pattern along the [112] zone axis and b) this associated HRTEM image.
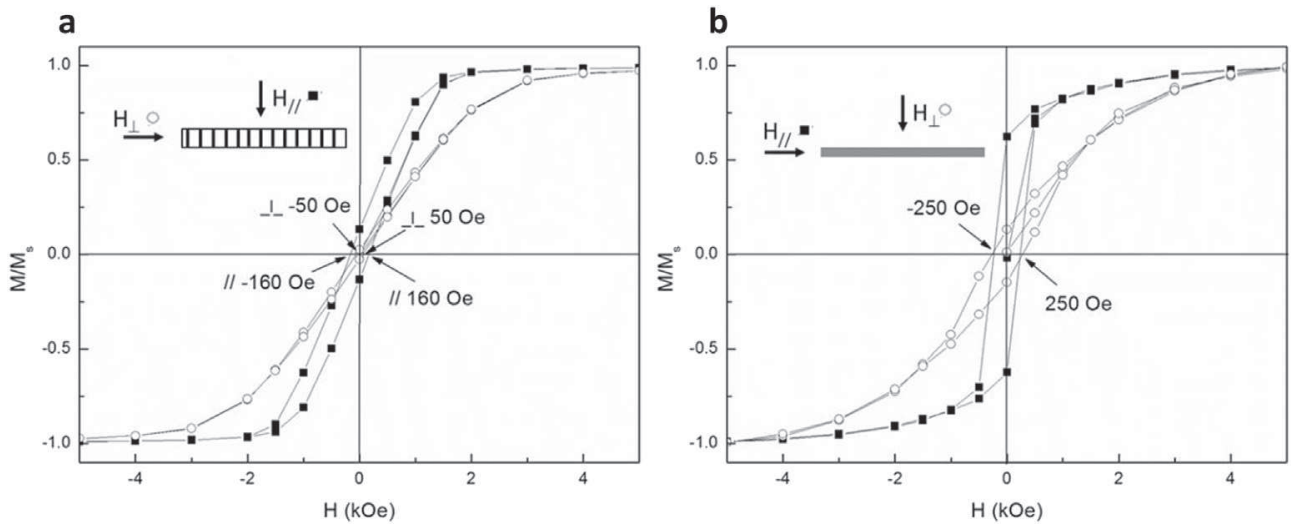

Fig. 3. Magnetic hysteresis loop for (a) Ni NWs and (b) the P(VDF-TrFE)/Ni NWs 0.3 vol\% at $300 \mathrm{~K}, \mathrm{H}$ is applied perpendicularly and in parallel to the Ni NWs and the film direction respectively $(\mathbf{\square})$ parallel field, $(\bigcirc)$ perpendicular field.

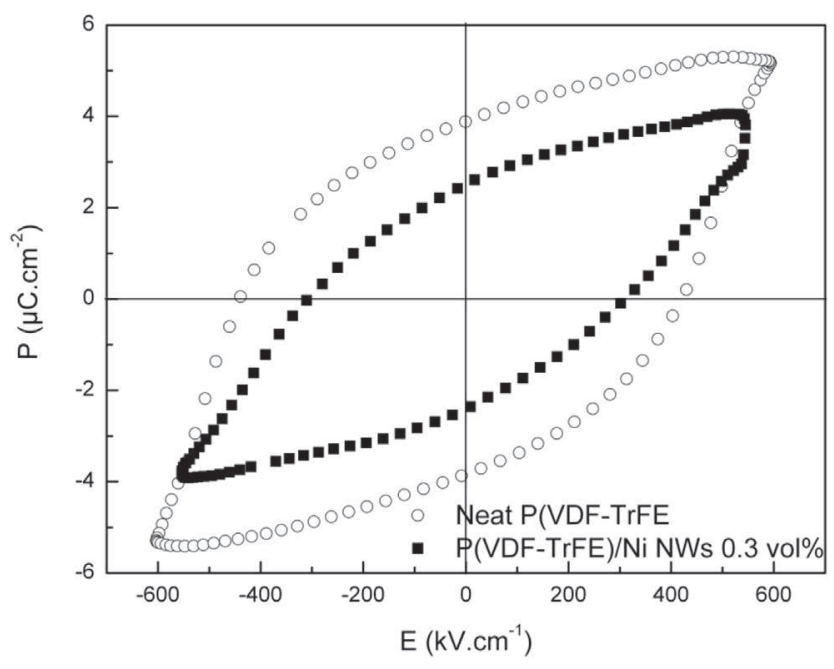

Fig. 4. Polarization hysteresis loop for neat $\mathrm{P}(\mathrm{VDF}-\mathrm{TrFE})$ and $\mathrm{P}(\mathrm{VDF}-\mathrm{TrFE}) / \mathrm{Ni}$ NWs $0.3 \mathrm{vol} \%$.

electric field of $60 \mathrm{kV} \mathrm{mm}^{-1}$. The remnant polarizations measured when $\mathrm{E}=0$ are $3.9 \mu \mathrm{C} \mathrm{m} \mathrm{m}^{-2}$ and $2.5 \mu \mathrm{C} \mathrm{m}^{-2}$ for neat $\mathrm{P}(\mathrm{VDF}-\mathrm{TrFE})$ and the $\mathrm{P}(\mathrm{VDF}-\mathrm{TrFE}) / \mathrm{Ni} \mathrm{NW} 0.3 \mathrm{vol} \%$ respectively. The coercive field values are $440 \mathrm{kV} \mathrm{cm}^{-1}$ and $307 \mathrm{kV} \mathrm{cm}^{-1}$ for neat $\mathrm{P}(\mathrm{VDF}-\mathrm{TrFE})$ and composite respectively. The piezoelectric coefficient $d_{33}$ has also been measured for the two samples in the direction 3 (perpendicularly to the composite film direction and in parallel to the polarization direction). The values are $-20 \mathrm{pC} \mathrm{N}^{-1}$

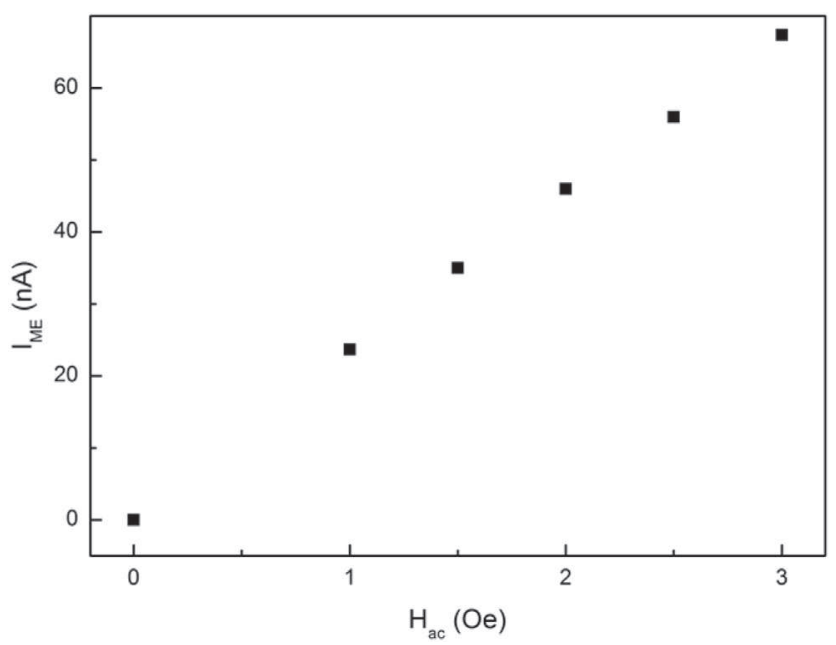

Fig. 5. Magnetoelectric current for $\mathrm{P}(\mathrm{VDF}-\mathrm{TrFE}) / \mathrm{Ni}$ NWs $0.3 \mathrm{vol} \%$ as a function of $\mathrm{H}_{\mathrm{ac}}$ at $\mathrm{f}=1 \mathrm{kHz}$. 
and $-7 \mathrm{pC} \mathrm{N}^{-1}$ for neat $\mathrm{P}(\mathrm{VDF}-\mathrm{TrFE})$ and $\mathrm{P}(\mathrm{VDF}-\mathrm{TrFE}) / \mathrm{Ni} \mathrm{NW}$ 0.3 vol\% respectively.

The composite ME coefficient has been measured along the direction $3 . \mathrm{A} \mathrm{H}_{\mathrm{dc}}$ scanning showed that the magnetoelectric current $\mathrm{I}_{\mathrm{ME}}$ is independent from $\mathrm{H}_{\mathrm{dc}}$. The following measurements are made with $\mathrm{H}_{\mathrm{dc}}=0$. The variation of the ME current $\mathrm{I}_{\mathrm{ME}}$ has been reported as a function of the magnetic field $\mathrm{H}_{\mathrm{ac}}$ and the frequency in Figs. 5 and 6 respectively. At this frequency range, $\mathrm{I}_{\mathrm{ME}}$ increases and evolves linearity with $\mathrm{H}_{\mathrm{ac}}$ and the frequency. This phenomenon is coherent with the magnetoelectricity theory. If these measurements had been performed close to the resonance frequency, a resonance peak associated with the electromechanical resonance would have been observed [23].

\section{Discussion}

On the SEM-FEG image (Fig. 1a and b), individual Ni nanowires are observed. They have no affinity with acetone which allows a homogeneous dispersion in this solvent. They were not damaged after sonication treatment. The Ni NWs bundle shows that their lengths are $50 \mu \mathrm{m}$. Their size corresponds to AAO membrane thickness and the size dispersion is insignificant.

Fig. 1c and d shows a Ni NWs uniform distribution throughout the $\mathrm{P}(\mathrm{VDF}-\mathrm{TrFE})$ matrix and no micron size aggregates are observed. Indeed, Ni NWs have no affinity in acetone and they kept their homogeneous dispersion in the polymer.

Thanks to the bright field TEM image, it is possible to determinate Ni NWs diameter. Fig. 2a shows a $200 \mathrm{~nm}$ diameter Ni NW. This value confirms the size predicted by the AAO membrane pores diameter. The aspect ratio of Ni NWs was estimated at 250 (using the result of SEM en TEM study). These observations indicate the interest of this method to obtain reproducible Ni NWs.

The SAED pattern (inset Fig. 2a) and the HRTEM image (Fig. 2b) are characteristic of a monocrystalline NW. The spacings in the SAED pattern are in good agreement with spacings of the fcc $\mathrm{Ni}$ (space group Fm-3m, $a=3.5239 \AA$ ).

According to the hysteresis cycle represented in Fig. 3a, a strong anisotropy is evidenced by the both lower $\mathrm{H}_{\mathrm{C}}(50 \mathrm{Oe})$ and squareness $(0.03)$ values at the perpendicular field direction to the Ni NWs (out-plane with the AAO template). Such anisotropy has been observed with magnetic nanowires [16,17,24-28] or nanotubes $[29,30]$. The anisotropy has been previously studied by Han [31] who showed that it was led by three contributions: the shape

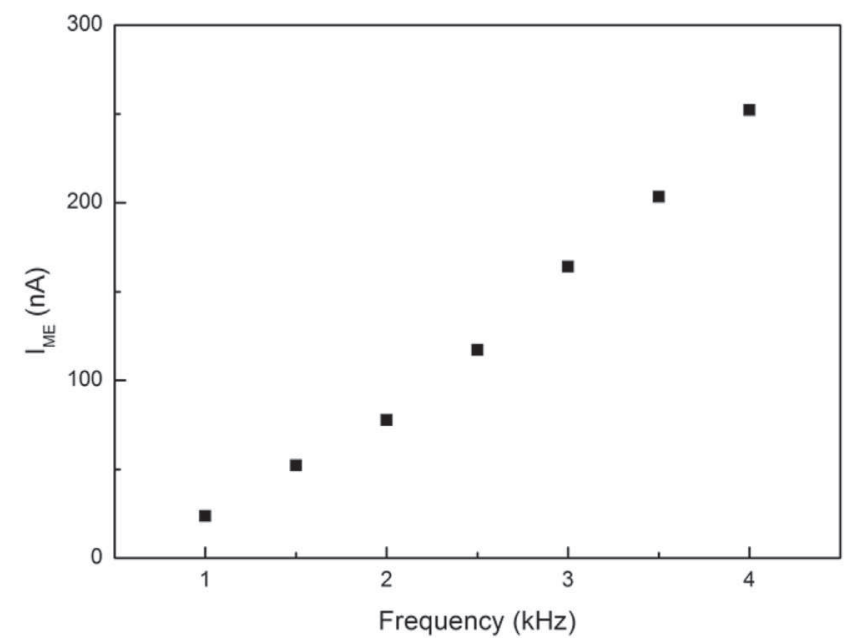

Fig. 6. Magnetoelectric current for $\mathrm{P}(\mathrm{VDF}-\mathrm{TrFE}) / \mathrm{Ni}$ NWs $0.3 \mathrm{vol} \%$ as a function of the frequency at $\mathrm{H}_{\mathrm{ac}}=1$ Oe. anisotropy due to the individual wires which induces a magnetic easy axis (parallel with the wire direction), magnetostatic coupling among the wires which leads to a magnetic easy axis (perpendicular with the wires direction), and the magnetocrystalline anisotropy which induces a parallel magnetic easy axis if the NWs microstructure is monocrystalline. The higher values of coercivity and squareness at the parallel direction show that the magnetocrystalline and the shape anisotropies are predominant over the magnetostatic coupling among the NWs. The coercivity and squareness values are similar to the values found in literature for the same particles diameter [32,33]. Although, we can find higher values in several articles for lower diameter particles [34,35]. Indeed, decreasing the NWs diameter raises coercivity and the magnetic hysteresis hardness [36]. Anisotropy is also observed by studying at the composite magnetic hysteresis loop on Fig. 3. The cryofracture SEM-FEG images (Fig. 1c and d) allow us to observe that the Ni NWs are preferentially oriented in the film direction, due to the hot melt process. The magnetic easy axis is then along the NWs direction. This observation confirms the three contributions previously given. The low NWs concentration in $\mathrm{P}(\mathrm{VDF}-\mathrm{TrFE})$ induces a magnetostatic coupling decrease which increases the squareness.

Fig. 7 shows the coercivities and the squarenesses of Ni NWs (a) and $\mathrm{P}(\mathrm{VDF}-\mathrm{TrFE}) / \mathrm{Ni} \mathrm{NW} 0.3 \mathrm{vol} \%$ composite (b) respectively, as functions of the temperature. The temperature influence of the $\mathrm{Ni}$ NWs in alumina template on magnetic properties is negligible. For $\mathrm{P}(\mathrm{VDF}-\mathrm{TrFE}) / \mathrm{Ni} \mathrm{NW}$, the composite coercivity decreases when the temperature increases. It has been associated with the polymer mobility increase near $\mathrm{T}_{\mathrm{g}}$ ( $\mathrm{T}_{\mathrm{g}}$ is equal to $240 \mathrm{~K}$ for $\mathrm{P}(\mathrm{VDF}-\mathrm{TrFE})$ ). This phenomena has been observed for polyamide 12 filled with Sm-Co particles [37].

The electric hysteresis loops on Fig. 4 show that the remnant polarization and the coercive field values are strongly dependent from the matrix filling. Indeed, the hysteresis loop area is lower for the composite. The higher $\mathrm{d}_{33}$ value of the neat $\mathrm{P}(\mathrm{VDF}-\mathrm{TrFE})$ confirms the difficulty to polarize the $\mathrm{P}(\mathrm{VDF}-\mathrm{TrFE})$ filled with conductive particles. Nevertheless, the $\mathrm{P}(\mathrm{VDF}-\mathrm{TrFE}) / \mathrm{Ni}$ NWs $0.3 \mathrm{vol} \% \mathrm{~d}_{33}$ is significant. In order to know the crystallinity influence on neat $\mathrm{P}(\mathrm{VDF}-\mathrm{TrFE})$ and its composite $\mathrm{d}_{33}$ values, differential scanning calorimetry measurements have been performed with these two samples. The crystallinity of 53.6 and $49.5 \%$ for neat $\mathrm{P}(\mathrm{VDF}-\mathrm{TrFE})$ and $\mathrm{P}(\mathrm{VDF}-\mathrm{TrFE}) / \mathrm{Ni} \mathrm{NWs} 0.3 \mathrm{vol} \%$ respectively is considered as constant. It confirms that $\mathrm{d}_{33}$ is not dependent from the $\mathrm{P}(\mathrm{VDF}-\mathrm{TrFE})$ physical structure evolution, but from poling difficulties in presence of Ni NWs (decrease of electrical local field and increase of sample heterogeneity).

Thanks to the equations (7) and (8), the ME coefficient $\alpha_{\mathrm{E}}$ has been calculated and reached the value of $237 \mathrm{~V} /(\mathrm{m} \mathrm{Oe})$ at $4 \mathrm{kHz}$. This value is compared by the ones found in the literature $[8,9,38-43]$ reported in Fig. 8 . The ME coupling is due to the strain produced by the magnetic Ni NWs on the piezoelectric matrix. When the NWs are submitted to a magnetic field, they tend to orientate in the direction of the magnetic field due to their anisotropy. This orientation produces a strain on the piezoelectric matrix which is converted in electrical charges. Most of the ME composites in the literature are multilayer which decreases greatly the surface contact and thus the ME coupling. The value obtained for $\mathrm{P}(\mathrm{VDF}-\mathrm{TrFE}) / \mathrm{Ni} \mathrm{NW}$ composite is in the same magnitude as composites containing PZT. In comparison with composites with a $\mathrm{P}(\mathrm{VDF}-\mathrm{TrFE})$ matrix the $\alpha_{\mathrm{E}}$ coefficient measured in this work is largely higher. This can be explained by a high surface contact between the ferromagnetic particles and the piezoelectric matrix thanks to a homogeneous dispersion shown in SEM cryofracture. Our high $\alpha_{\mathrm{E}}$ value can also be explained by the Ni NWs high aspect ratio. Previous studies on polymer matrix composites were carried 

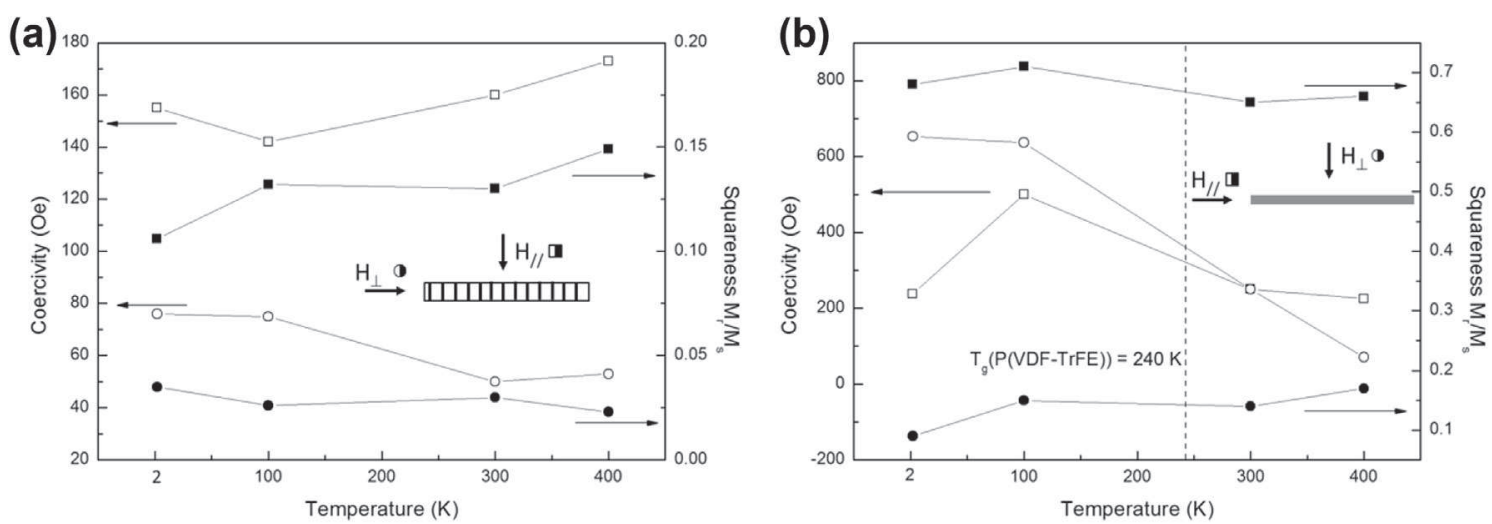

Fig. 7. (a) Ni NWs and (b) P(VDF-TrFE)/Ni NWs 0.3 vol\% composite positive coercivities ( $\forall,-)$ and squarenesses (!,,) as functions of the temperature.

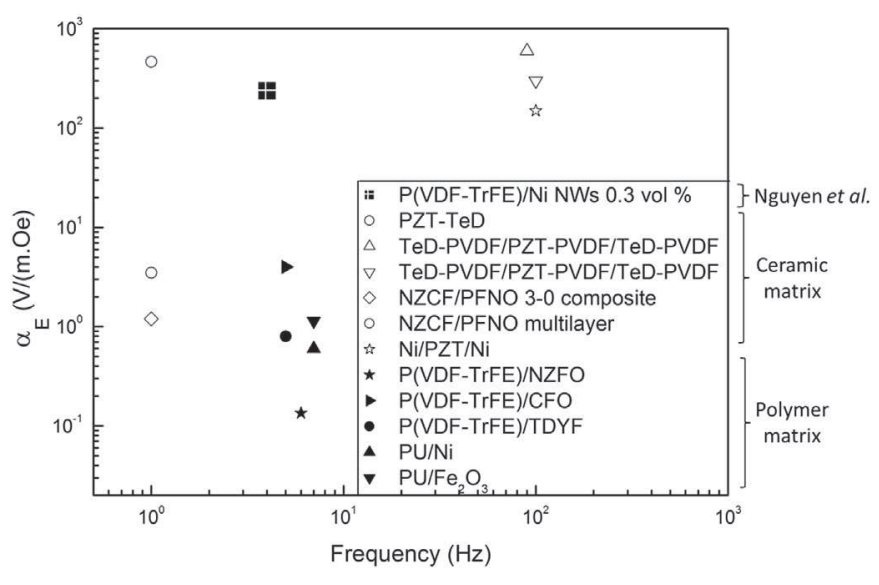

Fig. 8. Comparison of $\mathrm{P}(\mathrm{VDF}-\mathrm{TrFE}) / \mathrm{Ni}$ NWs $0.3 \mathrm{vol} \%$ magnetoelectric coefficient with other composites from the literature [8,9,38-43] with NZCF: $\mathrm{Ni}_{0,3} \mathrm{Zn}_{0,62} \mathrm{Cu}_{0,08} \mathrm{Fe}_{2} \mathrm{O}_{4}$; PFNO: $\mathrm{Pb}\left(\mathrm{Fe}_{0,5} \mathrm{Nb}_{0,5}\right) \mathrm{O}_{3}$; TeD: Terfenol-D; PZT: $\mathrm{Pb}\left(\mathrm{Zr}_{\mathrm{x}}, \mathrm{Ti}_{1-\mathrm{x}}\right) \mathrm{O}_{3}$; CFO: $\mathrm{CoFe}_{2} \mathrm{O}_{4}$; TDYF: $\mathrm{Tb}_{0,27}-\mathrm{xDy}_{0,73-\mathrm{y}} \mathrm{Y}_{\mathrm{x}+\mathrm{y}} \mathrm{Fe}_{2}$.

out with spherical particles. The NWs ability to deform and the strain implied by the magnetic field are supposed to be more important for high aspect ratio particles than spherical particles.

Contrary to the ceramic based composites, the sample elaborated in this study presents the following advantages: easy elaboration, ductility, low density.

\section{Conclusion}

$\mathrm{P}(\mathrm{VDF}-\mathrm{TrFE}) / \mathrm{Ni}$ NWs 0.3 vol\% composites magnetoelectric properties are described. At the microscopic level, the magnetic $\mathrm{Ni}$ nanowires were quasi-randomly distributed in the ferroelectric $\mathrm{P}(\mathrm{VDF}-\mathrm{TrFE})$ matrix. Magnetic properties have been investigated. The anisotropic nature of the Ni NWs had been highlighted by the highest coercivity and squareness in the parallel direction. The interaction between $\mathrm{Ni}$ NWs had also been evidenced by the improvement of the magnetic properties in the composite (a coercivity of 250 Oe and a squareness of 0.65 in the parallel direction). HRTEM images combined with SAED mode showed the monocrystallinity nature of the particles which allowed improving their magnetic properties. The P(VDF-TrFE)/Ni NW 0.3 vol\% composite had been polarized under an electric field of $60 \mathrm{kV} \mathrm{mm}^{-1}$ and obtained a significant piezoelectric coefficient in the direction 3 of $7 \mathrm{pC} \mathrm{N}^{-1}$. By associating the $\mathrm{Ni}$ NWs magnetism and the $\mathrm{P}(\mathrm{VDF}-\mathrm{TrFE})$ piezoelectricity, a multiferroic composite with a very high magnetoelectric coefficient was obtained. The magnetoelectric coefficient reached the value of $237 \mathrm{~V} /(\mathrm{m} \mathrm{Oe})$ which is the highest found in the literature for composites with a polymer matrix.

\section{References}

[1] C.W. Nan, N. Cai, Z. Shi, J. Zhai, G. Liu, Y. Lin, Large magnetoelectric response in multiferroic polymer-based composites, Phys. Rev. B 71 (1) (2005).

[2] V.B. Naik, R. Mahendiran, Magnetic and magnetoelectric studies in pure and cation doped BiFeO(3), Solid State Commun. 149 (19-20) (2009) 754-758.

[3] J. Ma, J.M. Hu, Z. Li, C.W. Nan, Recent progress in multiferroic magnetoelectric composites: from bulk to thin films, Adv. Mater. 23 (9) (2011) 1062-1087.

[4] M. Mostovoy, MULTIFERROICS A whirlwind of opportunities, Nat. Mater. 9 (3) (2010) 188-190.

[5] D. Chiba, M. Yamanouchi, F. Matsukura, H. Ohno, Electrical manipulation of magnetization reversal in a ferromagnetic semiconductor, Science 301 (5635) (2003) 943-945.

[6] M. Bibes, A. Barthélémy, Multiferroics: towards a magnetoelectric memory, Nat. Mater. 7 (2008) 425-426.

[7] C.W. Nan, N. Cai, L. Liu, J. Zhai, Y. Ye, Y. Lin, Coupled magnetic-electric properties and critical behavior in multiferroic particulate composites, J. Appl. Phys. 94 (9) (2003) 5930-5936.

[8] Y. Lin, N. Cai, J. Zhai, G. Liu, C.-W. Nan, Giant magnetoelectric effect in multiferroic laminated composites, Phys. Rev. B 72 (1) (2005).

[9] K. Bi, Y.G. Wang, W. Wu, Tunable resonance frequency of magnetoelectric layered composites, Sensors Actuat. A Phys. 166 (1) (2011) 48-51.

[10] J. Carvell, R. Cheng, P.A. Dowben, Q. Yang, Induced magneto-electric coupling in ferroelectric/ferromagnetic heterostructures, Appl. Phys. Lett. 103 (7) (2013) 072902.

[11] A. Mardana, M. Bai, A. Baruth, S. Ducharme, S. Adenwalla, Magnetoelectric effects in ferromagnetic cobalt/ferroelectric copolymer multilayer films, Appl. Phys. Lett. 97 (11) (2010) 112904.

[12] A. Mardana, S. Ducharme, S. Adenwalla, Ferroelectric control of magnetic anisotropy, Nano Lett. 11 (9) (2011) 3862-3867.

[13] D. Bhadra, M.G. Masud, S.K. De, B.K. Chaudhuri, Large magnetoelectric effect and low-loss high relative permittivity in 0-3 CuO/PVDF composite films exhibiting unusual ferromagnetism at room temperature, J. Phys. D Appl. Phys. 45 (48) (2012) 485002.

[14] J.X. Zhang, J.Y. Dai, L.C. So, C.L. Sun, C.Y. Lo, S.W. Or, H.L.W. Chan, The effect of magnetic nanoparticles on the morphology, ferroelectric, and magnetoelectric behaviors of CFO/P(VDF-TrFE) 0-3 nanocomposites, J. Appl. Phys. 105 (5) (2009) 054102.

[15] J. Zhang, W. Li, G.A. Jones, T.H. Shen, Composition-dependent structural and magnetic properties of $\mathrm{Co}_{[1-\mathrm{x}]} \mathrm{Pt}_{[\mathrm{x}]}(0.09 \leq \mathrm{x} \leq 0.86)$ nanowire arrays, J. Appl. Phys. 99 (8) (2006) 08Q502.

[16] H. Su, G. Ji, S. Tang, Z. Li, B. Gu, Y. Du, Geometry dependence of the annealing effect on the magnetic properties of Fe48Co52 nanowire arrays, Nanotechnology 16 (2005) 429-432.

[17] H. Pan, B.H. Liu, J.B. Yi, C. Poh, S. Lim, J. Ding, Y.P. Feng, C.H.A. Huan, J.Y. Lin, Growth of single crystalline $\mathrm{Ni}$ and Co nanowires via electrochemical deposition and their magnetic properties, J. Phys. Chem. B 109 (8) (2005) 3094-3098.

[18] C.G. Jin, W.F. Liu, C. Jia, X.O. Xiang, W.L. Cai, L.Z. Yao, X.G. Li, High-filling, largearea Ni nanowire arrays and the magnetic properties, J. Cryst. Growth 258 (3-4) (2003) 337-341.

[19] H. Zeng, R. Skomski, L. Menon, Y. Liu, S. Bandyopadhyay, D.J. Sellmyer, Structure and magnetic properties of ferromagnetic nanowires in selfassembled arrays, Phys. Rev. B 65 (2002), 134426-134421-134426-134428.

[20] C.Y. Kuo, K.H. Huang, S.Y. Lu, Structural effects on magnetic property of reciprocal opalline structures of iron-nickel alloys prepared with template- 
assisted electrodeposition, J. Taiwan Inst. Chem. Eng. 42 (1) (2011) 186-189.

[21] A. Lonjon, L. Laffont, P. Demont, E. Dantras, C. Lacabanne, New highly conductive nickel nanowire-filled P(VDF-TrFE) copolymer nanocomposites elaboration and structural study, J. Phys. Chem. 113 (2009) 12002-12006.

[22] B. Guiffard, J.W. Zhang, D. Guyomar, L. Garbuio, P.J. Cottinet, R. Belouadah, Magnetic field sensing with a single piezoelectric ceramic disk: experiments and modeling, J. Appl. Phys. 108 (9) (2010) 094901.

[23] D. Bhadra, M.G. Masud, S.K. De, B.K. Chaudhuri, Observation of large magnetodielectric and direct magnetoelectric behavior in LCMO/PVDF 0-3 nanocomposites, Appl. Phys. Lett. 102 (7) (2013) 072902.

[24] S. Xue, M. Li, Y. Wang, X. Xu, Electrochemically synthesized binary alloy FeNi nanorod and nanotube arrays in polycarbonate membranes, Thin Solid Films 517 (20) (2009) 5922-5926.

[25] L.H. Liu, H.T. Li, S.H. Fan, J.J. Gu, Y.P. Li, H.Y. Sun, Fabrication and magnetic properties of Ni-Zn nanowire arrays, J. Magn. Magn. Mater. 321 (20) (2009) 3511-3514.

[26] K. Nielsch, R.B. Wehrspohn, J. Barthel, J. Kirschner, U. Gosele, S.F. Fischer, H. Kronmuller, Hexagonally ordered $100 \mathrm{~nm}$ period nickel nanowire arrays, Appl. Phys. Lett. 79 (9) (2001) 1360-1362.

[27] C. Huang, P.P. Wang, W. Guan, S. Yang, L.M. Gao, L.Q. Wang, X.P. Song, R. Murakami, Improved microstructure and magnetic properties of ironcobalt nanowire via an ac electrodeposition with a multistep voltage, Mater. Lett. 64 (22) (2010) 2465-2467.

[28] X.F. Qin, C.H. Deng, Y. Liu, X.J. Meng, J.Q. Zhang, F. Wang, X.H. Xu, Magnetization reversal of high aspect ratio iron nanowires grown by electrodeposition, Trans. Magn. 48 (11) (2012) 3136-3139.

[29] W. Lee, R. Scholz, K. Niesch, U. Gosele, A template-based electrochemical method for the synthesis of multisegmented metallic nanotubes, Angew. Chem. Int. Ed. 44 (37) (2005) 6050-6054.

[30] H.R. Liu, Q.F. Lu, X.F. Han, X.G. Liu, B.S. Xu, H.S. Jia, The fabrication of CoPt nanowire and nanotube arrays by alternating magnetic field during deposition, Appl. Surf. Sci. 258 (19) (2012) 7401-7405.

[31] G.C. Han, B.Y. Zong, P. Luo, Y.H. Wu, Angular dependence of the coercivity and remanence of ferromagnetic nanowire arrays, J. Appl. Phys. 93 (11) (2003) 9202.

[32] C. Ross, M. Hwang, M. Shima, H. Smith, M. Farhoud, T. Savas, W. Schwarzacher, J. Parrochon, W. Escoffier, H. Bertram, F. Humphrey,
M. Redjdal, Magnetic properties of arrays of electrodeposited nanowires, J. Magn. Magn. Mater. 249 (1-2) (2002) 200-207.

[33] K. Ounadjela, R. Ferre, L Louail, JM. George J J Maurice, L. Piraux, S. Dubois, Magnetization reversal in cobalt and nickel electrodeposited nanowires, J. Appl. Phys. 81 (8) (1997) 5455.

[34] J. Zhang, Y. Jin, H. Wang, C. Ye, W. Tong, H. Wang, Growth and magnetic properties of single crystalline Ni nanowire arrays prepared by pulse DC electrodeposition, Sci. China Phys. Mech. Astron. 54 (7) (2011) 1244-1248.

[35] R. Ferre, K. Ounadjela, J. George, L. Piraux, S. Dubois, Magnetization processes in nickel and cobalt electrodeposited nanowires, Phys. Rev. B 56 (21) (1997) $14066-14075$.

[36] K. Nielsch, R.B. Wehrspohn, J. Barthel, J. Kirschner U. Gösele, S.F. Fischer, H. Kronmüller, Hexagonally ordered $100 \mathrm{~nm}$ period nickel nanowire arrays, Appl. Phys. Lett. 79 (9) (2001) 1360.

[37] M.I. Qadeer, S.J. Savage, M.S. Hedenqvist, High temperature magnetic properties of Sm-Co and Sm-Co/polyamide-12 materials: effects of temperature, particle size, and silanization, J. Mater. Sci. 48 (23) (2013) 8163-8170.

[38] D. Guyomar, B. Guiffard, R. Belouadah, L. Petit, Two-phase magnetoelectric nanopowder/polyurethane composites, J. Appl. Phys. 104 (7) (2008) 074902.

[39] P. Guzdek, M. Sikora, Ł. Góra, C. Kapusta, Magnetic and magnetoelectric properties of nickel ferrite-lead iron niobate relaxor composites, J. Eur. Ceram. Soc. 32 (9) (2012) 2007-2011.

[40] M. Szklarska-Łukasik, P. Guzdek, M. Dudek, A. Pawlaczyk, J. Chmist, W. Dorowski, J. Pszczoła, Magnetoelectric properties of Tb0.27-xDy0.73-yYx+yFe2/PVDF composites, J. Alloys Compd. 549 (2013) 276-282.

[41] N. Cai, J Zhai, C.W. Nan, Y Lin, Z Shi, Dielectric, ferroelectric, magnetic, and magnetoelectric properties of multiferroic laminated composites, Phys. Rev. B 68 (22) (2003)

[42] P. Martins, X. Moya, L.C. Phillips, S. Kar-Narayan, N.D. Mathur, S. LancerosMendez, Linear anhysteretic direct magnetoelectric effect in $\mathrm{Ni}(0.5) \mathrm{Zn}(0.5)$ $\mathrm{Fe}(2) \mathrm{O}(4) /$ poly(vinylidene fluoride-trifluoroethylene) 0-3 nanocomposites, J. Phys. D Appl. Phys. 44 (48) (2011).

[43] J.X. Zhang, J.Y. Dai, L.C. So, C.L. Sun, C.Y. Lo, S.W. Or, H.L.W. Chan, The effect of magnetic nanoparticles on the morphology, ferroelectric, and magnetoelectric behaviors of CFO/P(VDF-TrFE) 0-3 nanocomposites, J. Appl. Phys. 105 (5) (2009). 